\title{
A COMPREENSÃO AUTOPOIÉTICA DAS LIMITAÇÕES INTERPRETATIVAS DA FUNÇÃO SOCIAL DO CONTRATO
}

\section{THE AUTOPOIETIC COMPREENSION OF THE INTERPRETATIVE LIMITATIONS OF THE SOCIAL FUNCTION OF CONTRACT}

\author{
${ }^{1}$ Roberto José Covaia Kosop \\ ${ }^{2}$ José Edmilson de Souza Lima
}

\section{Resumo}

O presente artigo teve o intento de realizar uma abordagem sistêmica-autopoiética ao princípio da função social do contrato, consubstanciado no artigo 421 do Código Civil de 2002 e, consequentemente, de demonstrar as suas limitações interpretativas. Procurou-se evidenciar a indispensabilidade de um entendimento discursivo moderno na perspectiva de acrescentar à Teoria Geral do Contrato as consequiências sociais tão esperadas pelo legislador. Finalmente, estabeleceu-se que o a função social persiste em um acoplamento estrutural que não possibilita sua máxima efetivação, necessitando, assim, de uma revaloração sociológica.

Palavras-chave: Policontexturalidade; Interdisciplinaridade; Teoria dos Sistemas.

\begin{abstract}
This article had the intention to conduct a systemic-autoietic approach to the principle of the social function of the contract, embodied in the article 421 of the Civil Code of 2002 and, consequently, to demonstrate his interpretative limitations. It sought to highlight the indispensability of a modern discursive understanding with a view to add to the contract general theory the social consequences as expected by the legislator. Finally, it was established that the social function remains in a structural coupling that does not allow its maximum effectiveness, requiring a sociologial reevaluation.
\end{abstract}

Keywords: Policontextuality; Interdisciplinarity; Systems Theory.

\section{INTRODUÇÃO}

\footnotetext{
${ }^{1}$ Mestrando em Direito Empresarial e Cidadania (Bolsista da Coordenação de Aperfeiçoamento de Pessoal de Nível Superior - CAPES) e Bacharel em Direito pelo Centro Universitário Curitiba, UNICURITIBA - PR, (Brasil).E-mail: roberto_kosop@ hotmail.com

2 Pós-Doutor e Doutor em Meio Ambiente e Desenvolvimento pela Universidade Federal do Paraná, UFPR - PR, (Brasil). Pesquisador e Docente do Mestrado em Direito do Centro Universitário Curitiba, UNICURITIBA - PR, (Brasil). E-mail: zecaed@ hotmail.com
} 
A progressiva segregação das tendências modernas trouxe a liberação dos movimentos polarizados. Novos centros de convergências entre os mais variados grupos sociais começaram a surgir e a alta cultura passou a sofrer choques, inclusive o Direito, como o nascimento de um processo distinto que permeou as diversas áreas de vida social: a globalização ${ }^{3}$.

Diversas foram as correntes que abordaram, e ainda se debruçam, sobre este tema. Enquanto de um lado, haviam céticos que entendiam a globalização como uma construção meramente ideológica que de jeito algum pode servir como subsídio às decisões governamentais, há de outro, realistas que concordam com as novas ordens internacionais que dão preferência ao lucro trazido pelo câmbio de informações e da extraterritorialidade nascente.

Um lado ou outro, não há como negar que a globalização identifica uma tendência histórica de evolução estrutural, tanto na formação das nações, como no acelerar dos passos individuais rumo a formas inéditas de realidades sociais.

A noção do conceito universal aos poucos se substitui por globalizado. A universalização invocada pela intenção de produção e ordem ampla criou uma imensa intensificação de padrões nascentes desta comunicação moderna que deixa de considerar as barreiras geográficas, criando novas problematizações teóricas que não somente se operam nos planos semântico e sintático do Direito.

A dogmática jurídica, por sua vez, e, em especial a do Direito Contratual, encontra-se acomodada atrás da forte carga axiológica trazida pelo Princípio da Função Social do Contrato, resistindo a novas aberturas intra e interdisciplinares que estimulem transformações no conceito da própria figura do contrato.

\footnotetext{
${ }^{3}$ Por globalização, torna-se sadio o entendimento deste fenômeno como uma compreensão de espaço e tempo modificado pela crescente relação econômica e cultural das nações. Tanto em fluxo de capital, bens e pessoas, quanto na troca de informações e conceitos jurídicos, a globalização foi capaz de estreitar as barreiras existentes. "Tais fluxos são possíveis devido a suportes físicos (como sistemas de transporte, de comunicação e sistemas bancários), normativos (como as normas de comércio internacional) e simbólicos (como o inglês como língua franca)” (BARRETO, 2006, p. 380). Ainda, esta nova integração estreita entre os países ocasiona uma redução dos transpasses artificiais do comércio, propondo um caráter extraterritorial, ou seja, “a globalização tem sido acompanhada pela criação de novas instituições que tem se juntado às já existentes com o objetivo de trabalharem através das fronteiras" (STIGLITZ, 2002, p. 36).
} 
Em tal contexto multifacetado, o Direito necessita se manter em constante movimento com a finalidade de adequação às novas interações comunicativas. Procurar manter os valores, as regras e a tão almejada segurança jurídica não são atividades contrárias ao universo policontextural que o instrumento do contrato pode propor.

Percebe-se com a evolução histórica do Direito, o conceito de contrato tentou acompanhar os novos tempos, sendo que muitos códigos e diversos doutrinadores tentam encontrar uma definição própria. Carlos Alberto Bittar trata como "o acordo de vontades, por meio do qual se estabelecem, se modificam, ou se extinguem relações jurídicas de cunho patrimonial" (BITTAR, 1990, p. 10). Maria Helena Diniz, por sua vez, demonstra que "contrato é acordo entre a manifestação de duas ou mais vontades, na conformidade da ordem jurídica, destinado a estabelecer uma regulamentação de interesse entre as partes" (DINIZ, 2006, p. 9). Ou seja, resumidamente, o núcleo conceitual de Contrato se restringe àqueles pactos que extinguem, criam ou modificam as relações patrimoniais.

Outrossim, a doutrina geral leva em consideração a carga principiológica descrita na codificação civil, porém deixa de levar em consideração que a contemporaneidade "contempla a criação de um direito mais flexível com imperativos de ordem pública e cláusulas abertas na relação contratual” (LOPES JÚNIOR, 2012, p. 148). Desta forma, a discussão dos princípios da boa-fé objetiva, do equilíbrio econômico e da função social dos contratos, contemplam uma nova forma de ver o Direito "além da vontade das partes". Ocorre que, este além ainda sim é restrito a uma interpretação do contrato pelo contrato e do código pelo código.

Em especial o Princípio da Função Social do Contrato ${ }^{4}$, por mais válido que seja, não apresenta, por si só, um condão de aproximação às demais ciências e anseios sociais, senão por um olhar sistêmico-autopoiético e policontextural do contrato. Portanto, pretender-se-á adiante, não somente a crítica deste princípio, mas uma demonstração da capacidade dos instrumentos se adaptarem às novas realidades e sistemas sociais.

\footnotetext{
${ }^{4}$ Tal princípio se encontra se forma expressa no Código Civil de 2002, mais especificamente no artigo 421 com o seguinte texto: A liberdade de contratar será exercida em razão e nos limites da função social do contrato
} 


\section{DA FUNÇÃO SOCIAL DO CONTRATO}

A figura do Contrato passou (e ainda passa) por uma evolução valorativa, transcendendo as qualidades de igualdade formal e reciprocidade. As atenções, bem como os termos do pacto, são postas somente após a observância dos âmbitos econômicos, políticos e sociais nos quais irá ser inserido.

A partir de 1988, com a promulgação da Constituição Federal, ao modelo de contrato tem-se introduzido novas técnicas hermenêuticas e valores modernos ao ordenamento jurídico, necessitando uma remodelação das estruturas materiais e, sobretudo, das intenções individuais no tocante a formulação de obrigações e avenças.

A doutrina entra em consenso ao estabelecer que a função social da propriedade, princípio introduzido no inciso III do artigo 170 da Constituição Federal, é a nova faceta de obediência dos ditames sociais com desdobramentos necessários à livre iniciativa.

Destarte, o princípio da função social do contrato, preconizado no artigo 421 do Código Civil, estabelece uma limitação à liberdade de contratar dos indivíduos. Exalta um paradigma de aproximação social ao Direito, observando as responsabilidade sociais de impacto contratual. A princípio, o contrato não é tido somente como uma utilidade entre os contratantes, mas como um instrumento dialético para com a coletividade, "assim, pode ser vedado o contrato que não busca este fim" (MONTEIRO, 2012, p. 25).

O Direito Contratual se coloca ao lado das metas constitucionais, levando em conta as orientações legislativas de proteção ao bem comum e a ordem pública, aplicando como objetivo a garantia que os indivíduos exerçam seus direitos em consonância aos interesses sociais. No mesmo compasso, que a coletividade não restrinja completamente as liberdades individuais. Portanto, "faz-se indispensável atender ao fundamento da cidadania, a implicar a consideração do outro - incluindo a contraparte do negócio - como sujeito beneficiário da proteção estatal” (MAMEDE, 2014, p. 26) e, desta forma, o artigo 421 do Código Civil é fundamental para a garantia dos fundamentos constitucionais do Estado Democrático, prezando pela materialização das normas programáticas no âmbito privado. 
O contrato ainda existe para que as pessoas interajam com a finalidade de satisfazerem seus interesses e a função social do contrato serve para limitar a autonomia da vontade quando tal autonomia esteja em confronto com o interesse social e este deva prevalecer, ainda que essa limitação possa atingir a própria liberdade de não contratar (PEREIRA, 2009, p. 12).

A figura do Contrato foi submetida aos ditames morais e sociais do determinado momento histórico que foi submetido. A função social, por sua vez, não somente é razão, mas limitação para o exercício da liberdade de contratar e, por intermédio de tal carga axiológica, cada instrumento deve ser elaborado com a finalidade esperada pela sociedade na qual ele se insere. A função que desempenha no coletivo é de suma importância para sua existência e perpetuação no mundo jurídico. Tais pressupostos permitem a conclusão de que o princípio da função social do contrato o insere no âmbito macro, assim, repercutindo nos mais variados quadros coletivos de atuação individual. Para a sociedade, o conjunto global das relações jurídicas organizadas pelo Estado devem ser reverenciadas nas cláusulas específicas. "A função social do contrato também se manifesta, ad extra, pela contextualização histórica do negócio que deve assimilar determinadas variações relevantes, designadamente as crises, bem como as intervenções estatais." (MAMEDE, 2014, p. 33). Desta forma, o contexto social tem suma importância para a vida útil do contrato e, justamente em tal ponto, na conscientização doutrinária de que a interpretação e aplicação do artigo 421 do Código Civil devem ter como objetivo a construção de uma sociedade solidária, é que surgem problemáticas modernas que merecem a devida atenção e atualização.

Justamente pela função social do contrato ser "um motivo civilizador, que aproxima os agentes e dirime as distâncias e diferenças entre os mesmos" (GUILHERME, 2015, p. 111), o pacto entre as partes se assemelha à lei, nas suas devidas proporções e campos de incidência. Não há como negar, a importância interpretativa que se direciona a carga axiológica presente, a fim de que a mesma não se destine a mera limitação genérica, tal como se vê no presente, fazendo imperar uma concepção antiquada e individualista do direito privado.

Mesmo que em larga escala a doutrina tenha evoluído do positivismo imperante, o formalismo jurídico ainda é plural e concentrado na lógica entre as 
normas e institutos. Para tal corrente, as concepções subjetivas pouco importam à investigação de mérito do jurista, evidenciando, assim, uma exclusão deliberada de grande parcela do vasto campo epistemológico ainda desconhecido. "O mais das vezes, o formalismo interpretativo afunda as raízes na ideologia da separação do direito das ciências sociais, como puro dever-ser incontaminado pelo ser" (PERLINGIERI, 1997, p. 59). Como ciência, o Direito tem o dever de se comunicar, tanto entre si (intradisciplinaridade) quanto com as demais manifestações do sujeito (interdisciplinaridade). No âmbito privado, o contrato é, por excelência, mais que a manifestação de vontade, é a materialização do Direito. Logo, a função social e toda sua carga axiológica, deveria ser a união interdisciplinar. Ocorre que a mesma foi reduzida ao artigo 421, sendo condenada a uma prisão mono contextual preocupada em utilizar a função social como mero verificador de validade do contrato e não de sua eficácia social.

Ainda, o direito civil contemporâneo tem recaído em outro erro: a redução da função social à linguagem econômica. Como forma de interpretação do enunciado legislativo, a análise econômica do direito é extremamente válida e importante a evidenciar os reflexos à dogmática jurídica. Porém, é "necessário ter consciência que se é verdade que a análise custo-benefício contribui para realizar a eficiência, ela sozinha não consegue representar a especificação e complexidade da ciência jurídica" (PERLINGIERI, 1997, p. 64). A função social, vista apenas sob a ótica econômica, é teoria válida para a racionalização de um mercado e de seus fundamentos do negócio. Destarte, não exaure a interpretação do princípio e nem pode ser vista como o ponto final de evolução axiológica. Por sua vez, a interpretação sistêmica introduz um arcabouço conceitual de alto grau hábil a compreensão contratual, em especial, das limitações imperantes e da capacidade de estender os efeitos da função social à simples reprodução do artigo 421 da codificação civil.

\section{A CONTRIBUIÇÃO AUTOPOIÉTICA À TEORIA CONTRATUAL}


Frente a contemporaneidade, a figura do contrato é questionada pelos mais diversos fatores, vide a pluralidade presente em todos os âmbitos sociais, desde o momento de contratação, onde a igualdade entre os contratantes é de difícil percepção, senão impossível. Em sociedades complexas, é um dever a função social ser interpretada além do seu cárcere legislativo, a fim de que se entenda o contrato como um ser produtor de comunicações diversas entre pólos até então distintos.

O contrato, portanto, é um reflexo das dimensões autorreprodutivas dos sistemas jurídicos, possibilitando a relação do Direito com o campo socioeconômico e outros domínios da vida associativa. Sua dinâmica não pode ser estática ou somente se apoiar na função social, a colocando na posição final para os resultados sociais pretendidos, quando, em verdade, é um delineamento das vontades do legislador, ora, da sociedade.

Por sistema jurídico entende-se a percepção do conjunto das fontes dentro de um esquema conceptual que, por um lado, represente o sentido profundo de cada norma através de suas conexões com outras e das conexões destas com os princípios; por outro, que exprima a unidade entre a construção jurídica e a sua aplicabilidade social, através da radicação do direito na cultura entendida em sentido amplo (PERLINGIERI, 1997, p. 57-58).

Seguindo o espírito pós-moderno que evidenciou os efeitos contratuais na sociedade capazes de ultrapassar os contratantes e impactando toda a coletividade, apresentar-se-á um outro avanço interpretativo capaz de conciliar os verdadeiros objetivos da função social do contrato. Logo, a Teoria dos Sistemas tem sua aplicabilidade no mundo jurídico para explicar o contrato como um acordo comunicativo complexo que se estende a mera forma expressa do mesmo e do conceito legal.

Desta forma, "um sistema é um conjunto de partes coordenadas para realizar um conjunto de finalidades" (CHURCHMAN, 2015, p. 47) e o objetivo do cientista que analisa um sistema é anunciar os detalhes do plano total, do ambiente em que vive, sua finalidade e como pode ser mantido pelas atividades das pessoas que o usufruem, vide a premissa básica que "sistemas são orientados pelo seu ambiente não apenas ocasional e adaptativamente, mas também estruturalmente; e, sem ele, não poderiam existir" (LUHMANN, 2016, p. 33). 
A teoria sociológica propagada e introduzida ao Direito por Niklas Luhmann (1927 - 1998) demonstra que o núcleo da ciência jurídica é a comunicação e, portanto, o contrato é, antes de tudo, um acordo comunicacional. Em um período histórico no qual as alterações são velozes, os pactos não podem ser meramente um reflexo do momento estático, devendo acompanhar os anseios e mudanças sociais. A função social se vista como um fator determinante a acoplar a interdisciplinaridade ao direito contratual, permite por se efetivar como padrão de eficácia dos pactos.

O fechamento operativo do sistema social, dentro do qual o jurídico é um subsistema, significa que o sistema, para a produção de suas operações, remete-se às suas próprias operações e, assim, reproduz a si mesmo. Tratase de um modelo circular, no qual uma comunicação jurídica remete a outra imediatamente anterior, além de criar condições para a próxima comunicação. O fundamento de validade do direito não é buscado fora do direito. Somente o direito pode criar o direito, as comunicações jurídicas apenas são criadas por outras comunicações jurídicas (FERREIRA, 2011, p. 4-5).

Levando em conta um caráter social, o contrato é tido como mecanismo que acopla o mundo jurídico e econômico. Mesmo que tais sejam sistemas autônomos, que exigem condições mínimas para reprodução autopoiética, ou seja, a autorreprodução por seus próprios elementos internos (para o Direito é o binômio licito/ilícito), a figura do contrato é essencial para que ambos se choquem e transacionem entre si.

Luhmann desenvolve sua teoria com a pretensão de analisar as multifacetas sociais e jurídicas interligadas. A relação entre contingência e a complexidade é essencial para o entendimento desta teoria. O sociólogo se demonstra um verdadeiro empirista ao afirmar que o convívio é sensorialmente orientado, ou seja, as mais diferentes relações são constituídas a partir dos sentidos e, portanto, tem-se disposto ao homem as múltiplas possibilidades de ações. "O horizonte temporal da experiência e da ação humana não é apenas correlato da cautela individual, mas em sua forma genérica representa um aspecto da estrutura social que com ela se altera" (LUHMANN, 1985, p.166). Por complexidade, Luhmann entende como "aquele ponto de vista que talvez expresse da maneira mais intensiva as experiências com problemas na pesquisa sistêmica recente" (LUHMANN, 2016, p. 41) e por contingência "as possibilidades apontadas para as demais experiências poderiam ser 
diferentes das esperadas, ou seja, que essa indicação pode ser enganosa por referir-se a algo inexistente, intangível" (LUHMANN, 2007, p. 45). Logo, importante salientar que "a comunicação é a síntese entre informação, ato de comunicação e compreensão, sendo o elemento básico da sociedade" (BARRETO, 2013, p. 176).

Em tais conexões comunicativas se encontra a autopoiese ${ }^{5}$ e, consequentemente, os contratos passam a vigorar, autonomamente, em campos interdisciplinares férteis à devida eficácia da função social pretendida no artigo 421 do Código Civil.

A comunicação se torna um elemento nuclear do Direito, sendo que, sem esta troca, não há contrato. Ou seja, as estruturas tem que apresentar uma capacidade de conexão, "tem de possibilitar a capacidade de conexão de reprodução autopoiética pois, de outro modo, abandonarão sua própria base existencial" (LUHMANN, 2015, p. 56). As operações entre indivíduos são impulsionadas por diversos elementos sociais constitutivos. "Em outras palavras, a sociedade e seus subsistemas sociais articulam-se sempre comunicativamente, (auto)produzindo-se em um processo de redução constante da complexidade social” (BARRETO, 2013, p. 178-179).

No domínio de sistemas auto-organizacionais, a autopoiese se torna uma evolução social, pois permite tanto autonomia quanto a alteração do problema fundamental da teoria e das preocupações dos instrumentos. Logo, o contrato não somente tem uma característica viva e adaptável à realidade, como consegue exprimir a eficácia de seus impactos sociais transcendentais a mera interpretação genérica da norma. Uma questão de validade e limitação programática, até então como a doutrina majoritariamente entende, se torna um fundamento interdisciplinar de comunicação entre Sociedade e Direito. A Teoria dos Sistemas é imperativa na alteração da percepção daquele que vislumbra um pacto quanto dos que o executam perante a coletividade.

A reprodução autorreferencial, "autopoiética" no nível dos elementos, tem de se ater àquela tipologia de elementos que define o sistema. Por isso: reprodução! Assim, em sistemas de ação, tem-se sempre de reproduzir

$5 \mathrm{O}$ alcance da autopoiese vai muito alem da auto-organização. "A autopoiese não pressupõe, necessariamente, que aqueles tipos de operações com as quais o sistema se autorreproduz não exista de modo algum no ambiente do sistema" (LUHMANN, 2016, p. 54). Importante, ainda, salientar que o termo autopoiese é autoexplicativo, vindo do grego auto significando "próprio" e poiesis "criação". 
ações, e não células, macromoléculas, idéias etc (LUHMANN, 2016, p. 55).

Mesmo havendo uma comunicação extensa, a força constitucional implica no Direito somente ser afirmado pelo próprio Direito, logo, cabe a ele construir suas estruturas e estabelecer as formas de diálogo com as demais ciências sociais, vez que “os contratos são operações que possuem a capacidade de estabilizar uma diferença específica mediante a indiferença frente a todo o resto. Este é o benefício formal do contrato, sua relação específica de observação: diferença que faz diferença. (BARRETO, 2013, p. 180)", conquanto, em um sistema social complexo, frutifica a informação.

A função social do contrato, por si só, não é autosuficiente para tal entendimento, devendo ser apropriada por um caráter sistêmico que lhe dê diretrizes de ação e estabeleça um ambiente, mesmo mutável, de aplicação. Nota-se que a partir da visão sistêmica os "interesses sociais econômicos deverão estar sob o crivo da legalidade, desencadeando então as conseqüências previstas pelo princípio, como a realização do bem comum, dentre outras" (FERREIRA, 2011).

A comunicação policontextural e interdisciplinar completa uma visão sistêmica do meio social. A Teoria dos Sistemas Autopoiéticos, tendo como autopoiese a capacidade de um ser produzir outros semelhantes (tal como produções moleculares de adaptação biológica) é uma forma sofisticada de comunicação, no intuito de analisar a figura do contrato dentro da sociedade pós-moderna.

A função social do contrato necessita de uma maior amplitude científica do que o imperante formalismo jurídico, no tocante a interpretação contratual, para atingir marcos de eficácia e transcender a figura de um mero requisito de validade.

\footnotetext{
não basta atualmente conceber o contrato apenas em relação às exigências de cooperação, adaptação e boa-fé e confiança: deve-se conceber o contrato também em relação às exigências que, muitas vezes, se contradizem, de vários âmbitos de atuação que são ligados por meio da instituição do contrato (TEUBNER apud SARTORI, 2011, p. 188).
}

Isto se dá por diversos favores, mas principalmente pelo fato de que todos os discursos da sociedade, sejam estes da ciência, da política, do Direito, da educação, passam por filtros legais e são materializados por intermédio de contratos. Portanto, 
diante tal complexidade, é preciso haver uma comunicação entre os sistemas sociais e entender a figura do contrato como um ente acoplado de policontexturalidade e apto a criar sistemáticas autopoiéticas e complementares.

\title{
4 A POLICONTEXTURALIDADE INTERDISCIPLINAR
}

A representação do Direito a partir de uma visão jurídico-tecnicista, por mais que indispensável à criação de uma personalidade dogmática, não pode se perpetuar como o único caminho que o jurista deve trilhar. Muito pelo contrário. As novas tendências interpretativas ressaltam a possibilidade de abordagem dos questionamentos legais a partir de classificações e modelos de demais ciências e manifestações coletivas.

Não basta somente que haja uma revisão nas práticas educacionais para ultrapassar os obstáculos encontrados na formação das matrizes curriculares dos cursos de Direito. O essencial deve ser a capacidade de proporcionar à formação do cientista jurídico uma integralidade de vivências interdependentes com as diversas áreas do conhecimento, que somente irão engrandecer a cultura do Direito.

\begin{abstract}
A interdisciplinaridade não é uma simples técnica, mas uma postura, um modo de pensar e agir, é um exercício diário de raciocínio que ultrapassa os bancos escolares para interagir com o mundo complexo. Significa dizer que embora as unidades curriculares (disciplinas) sejam ministradas separadamente, devem interagir umas com as outras e com outras áreas do conhecimento, buscando, desta forma, explorar caminhos adequados a uma formação crítica, integral e transformadora (ALVES, 2006, p. 103).
\end{abstract}

Ao realizar a subsunção das normas jurídicas aos casos concretos, verificar-seá que há a presença de elementos não jurídicos em sua natureza. Interpretar o Direito, nada mais é que interpretar o próprio ser humano. Logo, não há como negar o pluralismo e a riqueza das perspectivas do ordenamento jurídico e suas dimensões técnicas, abrindo assim, um leque para a interdisciplinaridade ${ }^{6}$ tomar seu devido espaço.

\footnotetext{
6 “A pesquisa se opera a partir do campo teórico de uma das disciplinas em presença, que desenvolve problemáticas e hipóteses que confirmam parcialmente aquelas que a outra disciplina elabora por seu lado. Trata-se nesse caso, de uma articulação de saberes que acarreta, por abordagens sucessivas, como em diálogo, reorganizações parciais dos campos teóricos em presença”. (ARNAULD, 1999, p.
} 
Por tal método, deve-se antes de tudo pressupor que há uma organização ou uma força vinculativa entre as mais diversas ações disciplinares. $\mathrm{O}$ interesse comum de crescimento e atualização da filosofia jurídica é a força de orientação aos projetos de investigação comum.

Esta nova concepção de ensino, e principalmente de pesquisa, que transborda a apresentação simples de disciplinas isoladas, serve como tendência a não somente integralizar o sistema de interpretação jurídica, mas de torná-lo harmônico e acessível. Assim, "a compreensão dos textos jurídicos é um processo que visa alcançar uma forma de conhecimento" (PERLINGERI, 1997, p. 66). O intérprete coopera na produção do sentido e, portanto, o universo contratual deve transcender à positividade embutida no tocante a função social. Sendo o contrato um acordo comunicacional que estende a linguagem jurídica, a teoria dos sistemas permite a evolução autopoiética para a percepção do caráter extralingüístico que a função social detém, ultrapassando as barreiras do artigo 421 do Código Civil para se encontrar no campo social.

A ampliação da noção de direito positivo e a sua abertura para noções e valores não literalmente e não explicitamente subsuntos nos textos jurídicos permite a superação da técnica da subsunção e a prospectação mais realística da relação dialética e de integração fato-norma, em uma acepção unitária da realidade (PERLINGERI, 1997, p. 68).

A perspectiva intertextual, proveniente da Teoria dos Sistemas, permite observar o conceito além do seu acoplamento estrutural. "Tal perspectiva permite observar além da mera relação entre sistemas sociais autopoiéticos, permitindo contatar a problemática contratual em seu cerne discursivo-comunicativo" (BARRETO, 2013, p. 183). O contrato, como projeto discursivo, vai além da perspectiva de Luhmann acima apresentada, possibilitando uma conciliação operacional entre diferentes sistemas. Os pactos expressos devem acompanhar a complexa realidade pluralista jurídica e, dentro do ordenamento jurídico brasileiro, a função social deve ser analisada sob o enfoque sistêmico e discursivo para possibilitar uma devida efetivação de suas pretensões sociais.

95.). A interdisciplinaridade, portanto, é chamada para operar uma aproximação dentre duas ciências e/ou linguagens, sendo em especial, uma delas dogmática e a outra componente às ciências sociais. 
O contrato, em especial a função social deste, merece ser revista em suas bases epistemológicas para a adequação da perspectiva sociológica atual que vivencia uma modernidade em constante evolução. Comunicação é a palavra chave que liga os mundos até então não correlatos.

[...] não se está aqui a negar a existência de um déficit de racionalidade no Direito, o que é mais do que evidente e que tais movimentos já apontam. Apenas afirma-se que este déficit é resultado de uma visão simplista da racionalidade [...]. É exatamente isso que o Direito Policontextural vai afirmar (DUTRA, 2013).

Ao direito privado, deve ter atribuída a policontexturalidade para que este não mais permaneça isolado em suas estruturas, em especial, retirando a eficácia da função social, como está no presente. $\mathrm{O}$ entendimento do contrato como um instrumento que possibilite a interdiscursividade permite, não somente a reconstrução do mesmo, mas que sejam repensados seus efeitos perante terceiros.

As observações de Gunther Teuber sobre a policontexturalidade contribuem para uma observação mais detalhada do contrato, pois passam a representar, além das obrigações tradicionais, um discurso tecnológico, científico, social, entre outros. Logo, os direitos e as obrigações, estabelecidos em uma relação jurídica, precisam levar em conta uma função social frente às ameaças da policontexturalidade (ROCHA; MAIA, 2016).

Há, portanto, um movimento de transferências, tanto de obrigações quanto deveres ao domínio privado. Diante deste quadro, a necessidade de constitucionalizar este último âmbito se vê mais do que essencial ao seu desenvolvimento sadio como um instrumento de compreensão social. "Entre o Estado e a sociedade há uma pluralidade de setores sociais que tem de ser considerados, refletindo na compreensão e estruturação do direito" (MARQUES; LANSONI, 2014, p. 4). A pluralidade de discursos, agora aproximados, merece ser levada em consideração pela teoria do contrato, sendo possível a conciliação de um instrumento que, mesmo adaptável às realidades sociais múltiplas, apresente segurança jurídica para as partes contratantes. O direito privado tem a tarefa de reflexão da lógica interna destes setores, refletindo sobre cada racionalidade específica a partir da carga axiológica trazida pela função social do contrato. 
Se o critério de fundação do sistema privilegia de modo decisivo o conteúdo sobre a forma (contenutistico), sendo, portanto, fruto de elaboração, das correlações entre um e outro instituto, o sentido do sistema se deduz não no esplendido isolamento da relação do intérprete com o conteúdo de cada norma, mas sempre confrontando cada norma com todas as outras, verificando a sua coerência constitucional. Tal "conexão" é uma necessidade também lógica, como meio de conhecimento do ordenamento vigente e de suas efetivas potencialidades (PERILINGERI, 1997, p. 7778).

Identifica-se o direito privado nos âmbitos sociais onde se possibilita a existência de relações negociais espontâneas, sem intervenção estatal. A dogmática tradicional enfatizou o entendimento da autonomia privada como núcleo do direito privado, porém, “a unidade dogmática não atentou para o pluralismo atual expresso na multiplicação discursiva das autonomias privadas de uma sociedade complexa e diferenciada" (TEUBNER apud MARQUES; LANSONI, 2014, p. 5). Finalmente, o direito privado consegue repensar as formas de ação adequadas para a aproximação de esferas até então autônomas, relacionando-as por intermédio da função social.

\section{CONCLUSÃO}

$\mathrm{O}$ artigo objetivou analisar as limitações interpretativas sob um enfoque sociológico e sistemático, a partir da Teoria dos Sistemas introduzida ao direito por Niklas Luhmann. O instrumental permitiu uma observação complexa do instituto da função social, de modo critico, a tentar redefinir os parâmetros estabelecidos sobre tal. À dogmática jurídica se questiona, afastando-se do formalismo jurídico, ainda 
imperante, que engessa a doutrina, de modo a não buscar uma evolução plural da teoria contratual que acompanhe os anseios sociais.

Diante dos movimentos sociais constantes, faz-se necessário um processo de reconstrução, quase que ideológica, do direito contratual, recorrendo a uma interpretação crítica-construtiva, amparada na teoria autopoiética, com as devidas atualizações da policontexturalidade que permite a abertura dos sistemas sociais pertinentes.

A teoria dos sistemas permite o rompimento com o individualismo que impera no direito privado e, portanto, ao ampliar a força do discurso do sujeito, aproxima a função social do contrato de seu verdadeiro objetivo constitucional e racional.

Demonstrou-se que as concepções de Luhmann e Teubner são complementares, reconhecendo a complexidade social e a dinâmica das relações que permite um caráter autopoiético aproximado ao Direito com o objetivo de reestruturar as bases epistemológicas da interpretação contratual. Tanto a Teoria dos Sistemas quanto a policontexturalidade são formas de se observar as limitações auto-impostas pelo acoplamento estrutural do código. Finalmente, do ponto de vista sistêmico, é possível que haja comunicação entre sistemas e a função social deve ter o papel de aproximação dos mundos, se interpretada de forma plural e policontextural.

\section{REFERÊNCIAS}

ALVES, Elizete Lanzoni. A Docência e a Interdisciplinaridade: um desafio pedagógico. In: COLAÇO, Thais Luzia (Org.). Aprendendo a Ensinar Direito o Direito. Florianópolis: OAB/SC, 2006.

ARNAULD, André-Jean. Dicionário Enciclopédico de Teoria e Sociologia do Direito. 2. ed. Rio de Janeiro: Renovar, 1999.

BARRETO, Ricardo de Macedo Menna. Contrato e Autopoiese: uma observação sociológico-jurídica em Niklas Luhmann e Gunther Teubner. In: Revista Direito e Liberdade, ESMARN. v. 15. n. 3. p. 171-190. set./dez. 2013. 
BARRETO, Vicente de Paulo (Coord.) Dicionário de Filosofia do Direito. São Leopoldo: Unisinos, 2006.

BITTAR, Carlos Alberto. Direito dos Contratos e dos Atos Unilaterais. Rio de Janeiro: Forense Universitária, 1990.

CHURCHMAN, Charles West. Introdução à Teoria dos Sistemas. 2 ed. Tradução de Francisco M. Guimarães. Petrópoles: Vozes, 2015.

DINIZ, Maria Helena. Tratado Teórico e Prático dos Contratos. v.1. 6 ed. São Paulo: Saraiva, 2006.

DUTRA, Jéferson Luiz Dellavalle. Boa-fé, Equilíbrio Econômico e Função Social do Contrato: A possibilidade de uma reflexividade sistêmica através de Princípios Contratuais.

Disponível

em

<http://www.conpedi.org.br/manaus/arquivos/anais/brasilia/13_766.pdf.> Acesso em: 08.set.2016.

FERREIRA, Joélida J. Rocha. Análise do princípio da função social do contrato sob uma perspectiva autopoiética. In: Revista Eletrônica de Ciências Jurídicas. v. 1. n. 1. 2011.

GUILHERME, Luiz Fernando do Vale de Almeida. Função Social do Contrato e Contrato Social: análise da crise econômica. 2 ed. São Paulo: Saraiva, 2015.

LUHMANN, Niklas. El Derecho de La Sociedad. Tradução de Javier Torres Nafarrate. México: Universidade Iberoamericana, 2002.

Sistemas Sociais: esboço de uma teoria geral. Tradução de Antonio C. Luz Costa. Petrópolis: Vozes, 2016.

. Sociologia do Direito II. Tradução de Gustavo Bayer. Rio de Janeiro: Tempo Brasileiro, 1985.

MAMEDE, Gladston. Direito Empresarial Brasileiro. v.5. 2 ed. São Paulo: Atlas, 2014.

MARQUES, Carlos Alexandre Michaello; LANSONI, Liége Paim. Policontexturalidade e direito privado: Relações contratuais complexas em uma sociedade fragmentada na perspectiva de Gunther Teubner. Derecho y Cambio Social. v. 11. n. 36, 2014.

MONTEIRO, Washington de Barros. Curso de Direito Civil 5: direito das obrigações. 39 ed. São Paulo: Saraiva, 2012.

PEREIRA, Caio Mário da Silva. Instituições de Direito Civil. v. 3. 13 ed. Rio de Janeiro: Forense, 2009. 
PERLINGIERI, Pietro. Perfis do Direito Civil: introdução ao direito civil contemporâneo. Tradução de Maria Cristina de Ciccio. 3 ed. Rio de Janeiro: Renovar, 1997.

ROCHA, Leonel Severo; MAIA, Selmar José. A Perspectiva Sistêmica Autopoiética nas Relações Contratuais Frente à Contemporaneidade. Disponível em: 〈http://www.publicadireito.com.br/artigos/?cod=a7b0d547ea892113 > Acesso em 08.set.2016.

SARTORI, Liane Pioner. Mundos Contratuais: uma análise da obra de Gunther Teubner com enfoque no Direito Contratual Brasileiro In: Revista da Associação Brasileira de Pesquisadores em Sociologia do Direito - ABRASD. São Leopoldo: OIKOS, 2011.

STIGLITZ, Joseph E. A Globalização e seus Malefícios: a promessa não-cumprida de benefícios globais. Tradução de Bazán Tecnologia e Linguistica. São Paulo: Futura, 2002. 